Research Article

\title{
Evolution of High-Value Patents in Reverse Innovation: Focus on Chinese Local Enterprises
}

\author{
Tie Wei $(\mathbb{D}$ ) and Tingting Liu $(\mathbb{D}$ \\ Business School of Guangxi University, Guangxi, Nanning 530000, China \\ Correspondence should be addressed to Tie Wei; weitie@gxu.edu.cn
}

Received 26 April 2020; Revised 14 October 2020; Accepted 20 October 2020; Published 11 November 2020

Academic Editor: Yi Su

Copyright ( 92020 Tie Wei and Tingting Liu. This is an open access article distributed under the Creative Commons Attribution License, which permits unrestricted use, distribution, and reproduction in any medium, provided the original work is properly cited.

\begin{abstract}
The lack of high-value patents constraints the reverse innovation of developing countries' local enterprises. To explore how highvalue patents evolve within reverse innovation in these enterprises, this paper proposes a theoretical framework to analyze the relationships among technology, law, and market values for high-value patents and builds a three-dimensional Lotka-Volterra model of high-value patents under this framework. Using this model, this study explores the evolution path and the optimal conditions for the formation high-value patents. We take a local Chinese company, Huawei, as a case to test the theoretical analysis and make some managerial suggestions accordingly. Our research provides a theoretical basis for cultivating high-value patents in reverse innovation in local enterprises in China and other developing countries.
\end{abstract}

\section{Introduction}

Since the 21st century, a phenomenon has existed in which innovative products or technologies originating in developing countries or emerging markets spread back to developed countries. This situation is quite different than the traditional innovation model, in which new products or technologies are always created in developed countries and then spread to developing countries. The direction of this innovation's diffusion is "reverse," and Immelt [1] et al. call it "reverse innovation."

On the one hand, reverse innovation is not an accident for multinational companies of developed countries; it is an important innovation strategy to integrate global resources to gain a competitive advantage [2]. On the other hand, reverse innovation also brings new opportunities to local enterprises in developing countries. In recent years, reverse innovation led by local enterprises has greatly increased, for example, Huawei's 5G technology and India's Tata car $[3,4]$.

For most local enterprises in developing countries, the lack of high-value patents imposes constraints on their longterm competitiveness in reverse innovation [5]. However, existing research has not paid enough attention to the issue of high-value patents in reverse innovation in local enterprises.

A high-value patent is a concept that has been developed at the strategic level of an enterprise. This type of patent guarantees enterprises long-term and sustainable competitiveness in innovation competition [6]. The formation of high-value patents is not easy in reverse innovation in local enterprises. It is possible with the accumulation of technology and management experience for local enterprises to be competitive in the long-term and catch up with technology, which is a process of complex evolution.

A patent's value as an asset is usually reflected in three dimensions, i.e., technology, law, and market [7]. In reverse innovation, the value of the local enterprises' patents in these three dimensions changes frequently since their formation is restricted by the capital, technical ability, and market environment of local enterprises. For example, in the initial stage of reverse innovation, patents applied by local enterprises with the usual technology disadvantage do not necessarily have a very high value in the technology dimension. However, these patents may have a higher value in the market dimension since they can meet the needs of local consumers, 
with the large advantages of lower cost and huge demand. However, if the technology value of a patent is kept low, it is difficult for local enterprises to obtain a sustainable competitive advantage in the long term, especially when their new products flow reversely to developed countries and face global competition in the overseas market. At the same time, the intellectual property protection in developed countries is stricter than in developing countries. If the legal claims of a local enterprise's patent are not clear and stable enough overseas, then it faces the risk of infringement litigation, which would likely result in an invalid patent. Therefore, improving the law value of patents is inevitable for local enterprises when they enter developed counties' markets.

In the process of reverse innovation, the situation and capability of the local enterprises are changing with time, which is reflected in the changes in patents' value in the three dimensions. As a result, a high-value patent may be formed in this complex process. How does this process happen? How does the value of each of the three dimensions affect the others in this process? These are key issues in the cultivation of a high-value patent for local enterprises. However, there is still a gap in research in this area.

This process is similar to the evolution of an ecosystem $[8,9]$. The value of a patent in the three dimensions affects each other dimension and is influenced by the change in the situation during different phases of the reverse innovation, which is similar to the evolution of an ecosystem in which the relationships among populations change their influence on the external environment $[10,11]$. Therefore, this paper constructs a theoretical analysis framework of the value relationship of high-value patents in the following three dimensions, i.e., technology, law, and market. In this framework, we propose a three-dimensional Lotka-Volterra model to analyze high-value patents' evolution path and the optimal conditions for their formation in reverse innovation in local enterprises, and finally, we use a Chinese company, Huawei, as a case in the practical analysis.

The main contributions of this paper are as follows:

(1) It proposes a new theoretical analysis framework to discuss the issue of the formation of high-value patents. From the perspective of ecology, we explain high-value patents' relationships among the three dimensions of technology, law, and market. This study forms a new theoretical analysis framework that may help us explore more about how high-value patents are formed.

(2) It builds a novel three-dimensional Lotka-Volterra model to explore the evolution of high-value patents in reverse innovation in local enterprises. This model is a new extension of the classic Lotka-Volterra model that can specifically simulate the evolution and formation conditions of high-value patents in a complex situation.

(3) It analyzes the evolution of Huawei's high-value patent in reverse innovation and suggests some relative management policies. This study will help the developing countries' local enterprises cultivate their high-value patents in reverse innovation.

\section{Literature Review}

2.1. Reverse Innovation. In the beginning, research in this area focused on the issue of reverse innovation from the perspective of developed countries, including the degree of independence of multinational subsidiaries [12], the internal resistance to reverse innovation [13], etc. This research was mainly concerned with the phenomenon of reverse innovation that happened in emerging markets and was generally carried out by the transnational subsidiaries of developed countries [4]. This research discussed the obstacles and influencing factors encountered by subsidiaries when implementing reverse innovation in developing countries, including the independence, internal resistance, resource integration ability, strategic positioning, and intellectual property environment.

With the rise of local enterprises, reverse innovation led by developing countries has attracted the attention of researchers. This research is more concerned with case studies of local enterprises and discusses the factors that affect reverse innovation in local enterprises from different perspectives. For example, Nan [14] analyzed the case of the electronic information industry, identified the influencing factors of the local enterprise's reverse innovation, and proposed some strategies from the organizational and project levels. Xu et al. [15] and Yun [16] analyzed cases of some local technology service companies and proposed that organizational learning, industrial chain, technology chain construction, and international access are all important factors that affect the implementation of reverse innovation. In addition, Simone [13], Xu et al. [15], and Xu and Peng [17] discussed the impact of innovation networks, technological capabilities, and other factors on the implementation of reverse innovation led by local enterprises in developing countries, etc.

However, there is still little focus on the issue of the lack of high-value patents in reverse innovation in local enterprises. Some research has noted that the issue of whether to control superior intellectual property rights is a large difference between developed countries and developing countries in carrying out reverse innovation. However, there is still a lack of further in-depth discussion in this regard.

2.2. High-Value Patents. A high-value patent is a strategic concept that has been proposed to reflect the control of patents as a competitive strategy [18]. The high value is mainly embodied in the following three aspects: technology characters [19], claims in law [20], and market competition [21]. Wei et al. [7] and others believe that high-value patents mainly refer to patents with a high level of technological innovation, stable legal rights, and good market prospects. $\mathrm{Li}$ et al. [18] and others believe that high-value patents should reflect the strategic layout of enterprises. These are patents that enable enterprises to have high product competitiveness, market share and profit creativity. Ma and Zhao [21] also believe that high-value patents should highlight the high strategic value and market value. 
Therefore, high-value patents can be seen as having high value in these three aspects. First, these patents have a high value in technology, which means that the technology that is contained in the patents is a relatively high level, ensuring that the owners of the patents can use them to maintain a high control of the technology in the long term [19]. Second, high-value patents have a high legal value, which means that they have great legal stability, keeping them from being involved in infringement issues [20]. Third, high-value patents have a high market value, which means that they have a high strategic position that can control the market trend [22].

The value of a patent is ultimately reflected in its market performance, i.e., making an economic profit [22]. This is a result of the market monopoly that is given by law as a patent's unique technology innovation. Therefore, a patent's value in technology and law ultimately influences its market value. A patent is usually a kind of technical solution and is presented in some claims in law. A patent also has some important technical and legal characteristics. As a technical solution, the technology value of a patent is the basis for its final market value. Patents with high technology often help enterprises gain a long-term market monopoly position due to their technology advantages [19]. At the same time, patents enjoy exclusive rights according to the law. The stability of a patent's claims in the law also affects its market and technology value, that is, whether a patent makes it easy to infringe on others' patent rights or to be infringed upon by others also affects the realization of its technology value and the final market value [20].

Therefore, for high-value patents, their technology, market, and law values affect each other. Especially in the complex situation of reverse innovation, the interaction of these values in these three dimensions will lead to complex evolution, as in an ecosystem. However, how this complex evolution happens is still unknown.

\section{Theory and Model}

3.1. Value Relationship of High-Value Patents in the Three Dimensions. High-value patents can help support and guarantee that enterprises maintain a long-term advantage in competition. The values of high-value patents are mainly reflected in the three dimensions of technology, market, and law, which interact with each other.

First, we discuss the impact of the technology value on the market value. In general, the technology value determines the final market value of a patent since technology advantages can guarantee a monopoly in the market [23]. However, the advantage of the technology value transforming into the market value requires good external market opportunities. If the external market opportunities are not mature or available, then patents with high technology value may not bring a high market value. For example, Japanese companies first invented the two-dimensional code technology, but these patents did not obtain a good market value [24]. In contrast, Chinese companies with a technical disadvantage have had great success with this technology by developing it for mobile payment [25]. Patents should not only have excellent technical value but also have market opportunities to generate the market value. Some examples show that the pursuit of high technology value generates a high cost, and ultimately, the market value is restrained. For example, Kodak, which produces film, first developed digital camera technology but did not use it. Additionally, Xerox first developed the graphic operating system, etc. $[25,26]$. Therefore, the technology value may promote or inhibit the market value under different market conditions.

Second, we discuss the impact of the market value on the technology value. In a specific environment, patents with low technology value may also achieve high market value when there are good market opportunities. Some patented technologies in developing countries do not necessarily have high technology content; however, due to huge market demand, they can also achieve a high market value. For example, Huawei did not have an advantage in technology in the $3 \mathrm{G}$ and $4 \mathrm{G}$ eras, but its patents had high market value because of the great market demand in developing countries [27]. Usually, these kinds of patents would not maintain a long-term advantage in competition as they lack a high technology value. However, if the enterprises can use the profits gained from the short-term advantage in the market to invest in technology research and development, then it will eventually improve their patent's technology value. Therefore, patents with a high market value do not necessarily need to have a high technology value when they initially enter the market. However, in the long term, when facing fierce market competition, enterprises could invest more in technology to improve their patent's technology value [6]. Otherwise, a short-term advantage in the market could deceive enterprises and ultimately keep them out of competition since they lack a technology advantage. Therefore, the market value may promote or inhibit the technology value in different situations [28].

Third, we discuss the impact of the law value on the technology and market values. The law value is an important precursor to guarantee the technology value and market value. The law value lies in whether the patent has stable legal protection and depends on whether it is easy for others to infringe upon [29]. If the text of the patent application is written well and the technical scheme is obviously different from others, then its legal claims are stable and its law value is high. This is an important precursor for the realization of the technology value and market value. Patents with a low law value, even if they have high technology and market values, are easy to invalidate by a lawsuit or to be infringed upon by competitors. Therefore, a high law value is an important piece that is necessary to realize technical and market value. The law value of a patent can also promote or inhibit the technical and market value [30].

Fourth, we discuss how patents' technology and market values can also affect their law value. The legal protection of a patent is regional. In some regions, patents with a low law value may also obtain certain technology and market advantages. However, these advantages are unstable since enterprises may face troubles in the law area. If enterprises can use these advantages to improve their patent's law value, then the patent's law value will be promoted. Therefore, the 
patent's technology and market value can also promote or inhibit their law value.

Therefore, the relationships among technology, law, and market value are complex. Sometimes these relationships restrain each other, and sometimes, they promote each other. The relationships often change based on the enterprise's situation. Therefore, the formation of high-value patents is a long-term and continuous evolution process. In this process, the technology value is the important foundation of the market value, and the law value is the necessary guarantee for the market value so that they are finally embodied in a high market value through good market opportunities, as shown in Figure 1. This process is similar to an ecosystem, which evolves due to interactions among its inner factors and is affected by outer change [31].

3.2. Formation Path of High-Value Patents in Reverse Innovation of Local Enterprises. In reverse innovation, the formation of high-value patents in local enterprises is a complex, evolving process. Initially, a local enterprise's patents may have low technology values as they always follow the technology of developed countries. Additionally, their patent's law value may be low because developing countries usually have poor technology protection and local enterprises pay little attention to the protection of their intellectual property rights. Local enterprises mainly gain profits through low prices, cost advantage, and huge market demands. However, these advantages are limited in a local market and will not last when the market competition becomes more fierce. It is easy to be replaced by latecomers that have more advanced technology or lower costs. The low law value of the patent also makes local enterprises vulnerable to legal disputes and decreases their market advantage. Therefore, local enterprises that are thinking long term capitalize on the short-term and regional market advantage and increase their innovation investment to improve their patents' technology and law values, which may successfully turn the short-term advantage in a regional market into a long-term advantage in the international market, where reverse innovation in local enterprises occurs [6]. Therefore, we propose the formation path for high-value patents in reverse innovation in local enterprises, as shown in Figure 2.

\subsection{Model}

3.3.1. Lotka-Volterra Model. The Lotka-Volterra model was first used in nature for the analysis of competition and symbiosis among species and was later introduced into social science research $[32,33]$. Since the Lotka-Volterra model explains the evolution of complex ecosystems well $[34,35]$, we used it in our research to analyze the evolution process of high-value patents in reverse innovation in local enterprises. The Lotka-Volterra model is usually composed of a logistic growth function, which is used to express two species with a mutually influential relationship, and is expressed as follows [34]:

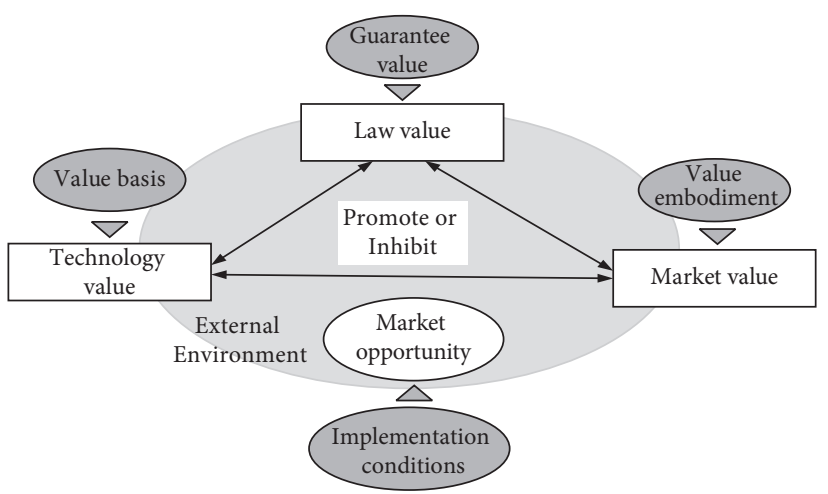

FIgURE 1: Value relationships of high-value patents.

$$
\left\{\begin{array}{l}
\dot{X}=\frac{\mathrm{d} X}{\mathrm{~d} t}=X\left(a_{1}-b_{1} X-c_{1} Y\right), \\
\dot{Y}=\frac{\mathrm{d} Y}{\mathrm{~d} t}=Y\left(a_{1}-b_{1} Y-c_{1} X\right),
\end{array}\right.
$$

where $X$ and $Y$ represent the total resources owned by two species $X$ and $Y$, respectively. $a_{i}$ and $b_{i}$ are the coefficients of the independent growth of the two species $\left(i=1,2\right.$, where $b_{i}$ is the limiting coefficient of species growth to resource consumption and to itself). $c_{i}$ is the growth coefficient of interaction among the species. The greater the absolute value of $c_{i}$ is the greater the influence between the two species.

The Lotka-Volterra model is a continuous time model. We transformed it into a discrete-time model as follows:

$$
\left\{\begin{array}{l}
X(t+1)=\frac{\alpha_{1} X(t)}{1+\beta_{1} X(t)+\lambda_{1} Y(t)}, \\
Y(t+1)=\frac{\alpha_{1} Y(t)}{1+\beta_{1} Y(t)+\lambda_{1} X(t)},
\end{array}\right.
$$

$X(t+1)$ and $Y(t+1)$ represent the total number of species $X$ and $Y$ in $t+1$ time, respectively. $X(t)$ and $Y(t)$ represent the total number of species in $t$ time.

(2) Equilibrium conditions and equilibrium points of the model:

\subsubsection{Lotka-Volterra Model of High-Value Patent Evolution in Reverse Innovation in Local Enterprises}

(1) Model construction and parameter determination:

In the three dimensions of technology, law, and market, the value of high-value patents is $V_{i},(i=1,2$, $3)$. The rate of change with time is $\dot{V}_{i}=\mathrm{dV}_{i} / \mathrm{dt} . a_{i}$ and $b_{i}$ represent the independent development coefficients of value in each dimension. $c_{i}$ and $d_{i}$ represent the mutual influence coefficients between the values of each dimension. The value changes of high-value patents in the three dimensions can be expressed as follows: 


$$
\left\{\begin{array}{l}
\dot{V}_{1}=\frac{\mathrm{d} V_{1}}{\mathrm{~d} t}=V_{1}\left(a_{1}-b_{1} V_{1}-c_{1} V_{2}-d_{1} V_{3}\right), \\
\dot{V}_{2}=\frac{\mathrm{d} V_{2}}{\mathrm{~d} t}=V_{2}\left(a_{2}-b_{2} V_{2}-c_{2} V_{1}-d_{2} V_{3}\right) \\
\dot{V}_{3}=\frac{\mathrm{d} V_{3}}{\mathrm{~d} t}=V_{3}\left(a_{3}-b_{3} V_{3}-c_{3} V_{1}-d_{3} V_{2}\right) .
\end{array}\right.
$$

Here, we convert the above equation into a discretetime equation:

$$
\left\{\begin{array}{l}
V_{1}(t+1)=\frac{\alpha_{1} V_{1}(t)}{1+\beta_{1} V_{1}(t)+\gamma_{1} V_{2}(t)+\delta_{1} V_{3}(t)}, \\
V_{2}(t+1)=\frac{\alpha_{2} V_{2}(t)}{1+\beta_{2} V_{2}(t)+\gamma_{2} V_{1}(t)+\delta_{2} V_{3}(t)}, \\
V_{3}(t+1)=\frac{\alpha_{3} V_{3}(t)}{1+\beta_{3} V_{3}(t)+\gamma_{3} V_{1}(t)+\delta_{3} V_{2}(t)} .
\end{array}\right.
$$

By using the nonlinear least square estimation, we calculated the value independent development coefficient and mutual influence coefficient of each dimension. The specific values of the parameters are as follows:

$$
\begin{aligned}
& a_{i}=\ln \alpha_{i}, \\
& b_{i}=\frac{\beta_{i} \ln \alpha_{i}}{\alpha_{i}-1}, \\
& c_{i}=\frac{\gamma_{i} \ln \alpha_{i}}{\alpha_{i}-1}, \\
& d_{i}=\frac{\delta_{i} \ln \alpha_{i}}{\alpha_{i}-1} .
\end{aligned}
$$

Positive and negative signs of $c_{i}$ and $d_{i}$ can reflect the interaction between the values. A positive sign indicates a relationship of promotion, a negative sign indicates inhibition, and zero indicates no correlation. Therefore, when the coefficients are all positive, it means that they exhibit mutual promotion, and vice versa. When the coefficients are positive and negative, it means that the promotion and inhibition are opposite to each other. When the mutual influence coefficients are zero and nonzero, it means that there is a one-way influence relationship.

According to the previous analysis, we list the positive and negative signs of $c_{i}$ and $d_{i}$ in the domestic and international market environment in Table 1.
When all of the equations in (3) are equal to zero, the maximum values in all three dimensions are obtained at the same time. This situation can be regarded as the optimal equilibrium condition for the formation of high-value patents. That is, under the condition of mutual promotion or restriction of the three dimension values, patents form the best high-value patents. The equilibrium conditions can be expressed as follows:

$$
\left\{\begin{array}{l}
\dot{V}_{1}=\frac{\mathrm{d} V_{1}}{\mathrm{~d} t}=V_{1}\left(a_{1}-b_{1} V_{1}-c_{1} V_{2}-d_{1} V_{3}\right)=0 \\
\dot{V}_{2}=\frac{\mathrm{d} V_{2}}{\mathrm{~d} t}=V_{2}\left(a_{2}-b_{2} V_{2}-c_{2} V_{1}-d_{2} V_{3}\right)=0 \\
\dot{V}_{3}=\frac{\mathrm{d} V_{3}}{\mathrm{~d} t}=V_{3}\left(a_{3}-b_{3} V_{3}-c_{3} V_{1}-d_{3} V_{2}\right)=0
\end{array}\right.
$$

The boundary conditions converging to an equilibrium state are as follows:

$$
\left\{\begin{array}{l}
\text { if } V_{1}>\frac{a_{1}-c_{1} V_{2}-d_{1} V_{3}}{b_{1}}, \text { then } \frac{\mathrm{d} V_{1}}{\mathrm{~d} t}<0 \\
\text { if } V_{2}>\frac{a_{2}-c_{2} V_{1}-d_{1} V_{3}}{b_{2}}, \text { then } \frac{\mathrm{d} V_{2}}{\mathrm{~d} t}<0 \\
\text { if } V_{1}>\frac{a_{3}-c_{3} V_{1}-d_{3} V_{2}}{b_{3}}, \text { then } \frac{\mathrm{d} V_{1}}{\mathrm{~d} t}<0
\end{array}\right.
$$

By reducing the dimension of (7), we obtain

$$
\left\{\begin{array}{l}
\frac{\mathrm{d} V_{2} / \mathrm{d} t}{\mathrm{~d} V_{1} / \mathrm{d} t}=\frac{\mathrm{d} V_{2}}{\mathrm{~d} V_{1}}=\frac{V_{2}\left(a_{2}-b_{2} V_{2}-c_{2} V_{1}-d_{2} V_{3}\right)}{V_{1}\left(a_{1}-b_{1} V_{1}-c_{1} V_{2}-d_{1} V_{3}\right)}=0 \\
\frac{\mathrm{d} V_{3} / \mathrm{d} t}{\mathrm{~d} V_{1} / \mathrm{d} t}=\frac{\mathrm{d} V_{3}}{\mathrm{~d} V_{1}}=\frac{V_{3}\left(a_{3}-b_{3} V_{3}-c_{3} V_{1}-d_{3} V_{2}\right)}{V_{1}\left(a_{1}-b_{1} V_{1}-c_{1} V_{2}-d_{1} V\right)}=0 \\
\frac{\mathrm{d} V_{3} / \mathrm{d} t}{\mathrm{~d} V_{2} / \mathrm{d} t}=\frac{\mathrm{d} V_{3}}{\mathrm{~d} V_{2}}=\frac{V_{3}\left(a_{3}-b_{3} V_{3}-c_{3} V_{1}-d_{3} V_{2}\right)}{V_{2}\left(a_{2}-b_{2} V_{2}-c_{2} V_{1}-d_{2} V\right)}=0
\end{array}\right.
$$

For the above equation to hold, the results of all three equations must be zero. Since $V_{i} \neq 0$, then

$$
\left\{\begin{array}{l}
a_{2}-b_{2} V_{2}-c_{2} V_{1}-d_{2} V_{3}=0 \\
a_{3}-b_{3} V_{3}-c_{3} V_{1}-d_{3} V_{2}=0 \\
a_{3}-b_{3} V_{3}-c_{3} V_{1}-d_{3} V_{2}=0
\end{array}\right.
$$

In the three-dimensional coordinate diagram (Figure 3), each of the above three equations represents a plane. They represent the maximum value degree of high-value patents in technology, law, and market. If there is an intersection point, then it is the equilibrium point, which is where we obtain the best high-value patents in the three dimensions, as shown in Figures 3(a) and 3(b) which shows that the three 


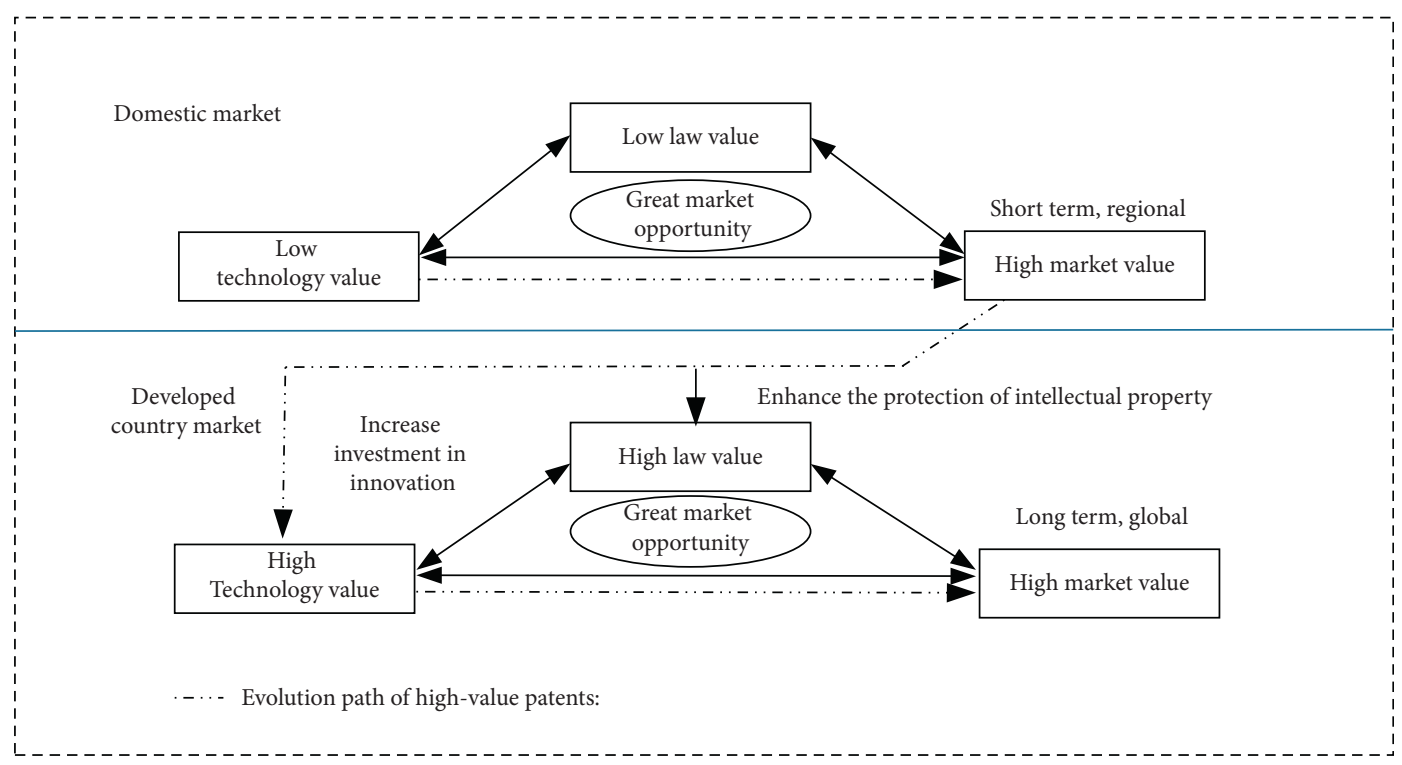

FIGURE 2: Formation path of high-value patents in reverse innovation in local enterprises.

TABLE 1: Relationships of the mutual influence coefficient.

\begin{tabular}{lcccccccccc}
\hline $\begin{array}{l}\text { Market } \\
\text { environment }\end{array}$ & $c_{1}$ & $c_{2}$ & $c_{3}$ & $d_{1}$ & $d_{2}$ & $d_{3}$ & Route & Relationship & Result \\
\hline Domestic & - & - & + & 0 & 0 & + & $\begin{array}{c}\text { Low technical value, } \\
\text { low law value, and high } \\
\text { market value }\end{array}$ & $\begin{array}{c}V_{1} \text { and } V_{2} \text { indicate a reciprocal inhibition, } V_{1} \text { and } \\
V_{3} \text { indicate a partial interest relationship, and } V_{2} \\
\text { and } V_{3} \text { indicate a partial interest relationship }\end{array}$ & $\begin{array}{c}\text { Short term and } \\
\text { regional high-value } \\
\text { patents }\end{array}$ \\
International & + & - & - & - & - & - & $\begin{array}{c}\text { High technical value, } \\
\text { high law value, and } \\
\text { high market value }\end{array}$ & $\begin{array}{c}V_{1} \text { and } V_{2} \text { indicate a mutual promotion, } V_{1} \text { and } \\
V_{3} \text { indicate a mutual promotion, and } V_{2} \text { and } V_{3}\end{array}$ & $\begin{array}{c}\text { Long term and global } \\
\text { high-value } \\
\text { patents }\end{array}$ \\
\hline
\end{tabular}

Note: the partial interest relationship is a kind of one-way relationship that is beneficial to one party and has no obvious impact on the other.

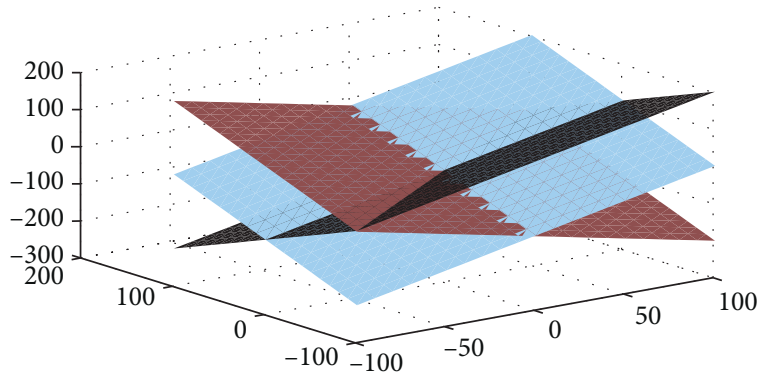

(a)

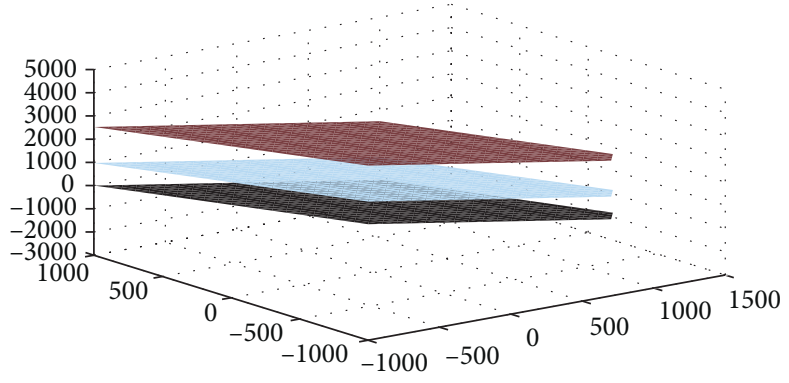

(b)

FIGURE 3: Equilibrium point of the three-dimensional coordinate diagram.

planes are parallel, and there is no intersection point, which indicates that there is no equilibrium point.

\section{Case Analysis}

4.1. Case Enterprise Selection and Data Collection. In this paper, we chose Huawei as the representative of local enterprises in reverse innovation. Huawei has been successful in reverse innovation in recent years. Its new products have made great progress in developing markets in developed countries, and it has obtained superiority in regard to technology and market competition. In the first quarter of 2019 global mobile market share report, Huawei's mobile market share was 15.7\%, which surpassed Apple [36, 37]. Particularly, in the field of next generation 5G technology, Huawei has achieved successful reverse innovation. Its $5 \mathrm{G}$ patents are at the leading level in the world, as shown in Figure 4.

In this paper, we used the Innography database to collect Huawei's data; we only selected invention patents to reflect 


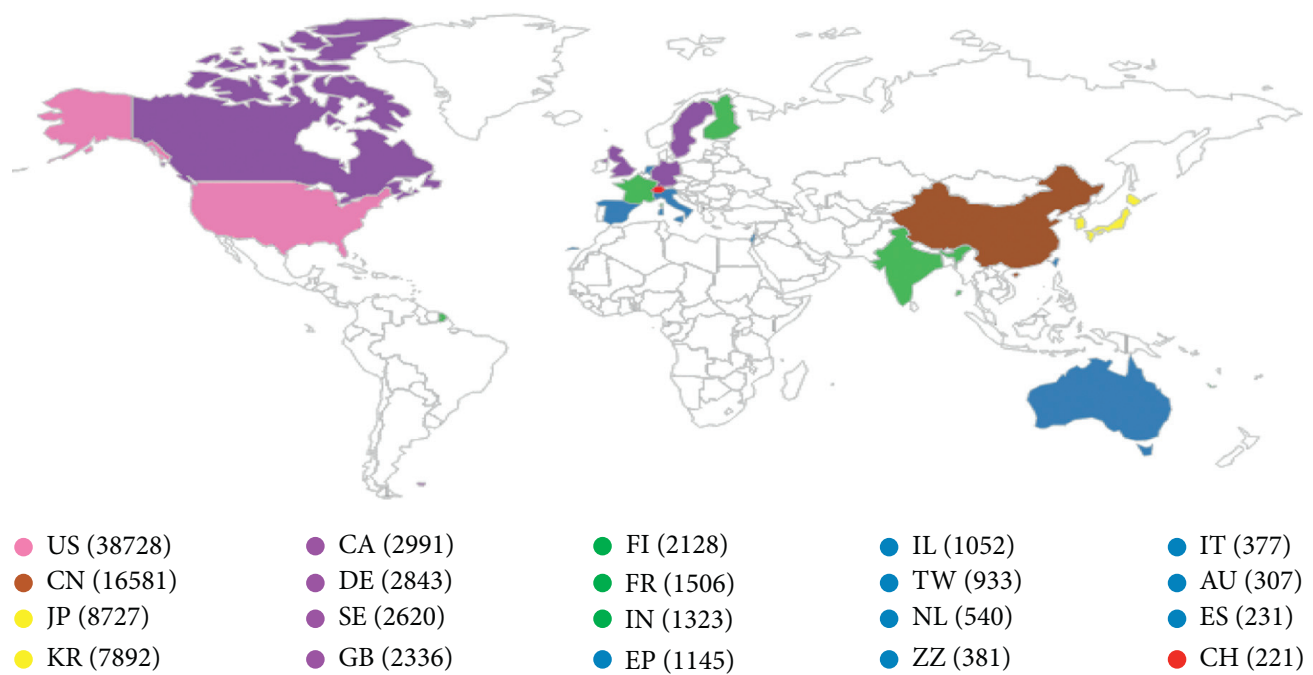

Figure 4: Global distribution of Huawei’s 5G patents from 2001 to 2018 (data from the Innography database (https://app.innography.com/).

the technical value(the scope of patent granting varies from country to country. However, these patents generally include invention patents belonging to technical solutions for new products (methods) with greater innovation. Therefore, the patents mentioned in this paper mainly refer to invention patents with greater technological content, excluding general utility model and design patents). Some studies show that Huawei has increased its R\&D efforts since 2001. Since the time of $2 \mathrm{G}$, there has been a focus on imitation innovation, and Huawei has been able to break the technology monopoly. The development of $5 \mathrm{G}$ has been a great breakthrough, and Huawei has gradually taken the leading position in the market. Therefore, we divided Huawei's reverse innovation into two stages since 2001. The first stage focused on the domestic market (2001-2011). In this stage, Huawei focused on technology introduction and imitation innovation and gained a competitive advantage in the domestic market. The second stage focused on developed countries (since 2011 to now). The strategic focus for this stage was on innovation ability and bringing the independently developed products to the developed country's market to obtain stable competitiveness.

With its development path, we collected Huawei's patents from January 1, 2001, to December 31, 2018, and selected patents with high values(according to the comprehensive scores of patent claims, patents of the same family, cite and cited, whether involved in the case, patent protection period, etc. A patent with a patent strength of more than 3 is a patent with high value). Finally, we collected 125,369 patents as a sample.

4.2. Measurement of Patent Value. We calculated the patents' values in technology, law, and market (see Appendix), as shown in Table 2.

From the data, all of the values in the three dimensions are rising, as shown in Figure 5.
TABle 2: Patent technology, law, and market values.

\begin{tabular}{cccc}
\hline Year & Technology value & Law value & Market value \\
\hline 2001 & 33 & 43 & 28 \\
2002 & 1711 & 2221 & 1522 \\
2003 & 3875 & 5037 & 3443 \\
2004 & 10993 & 14307 & 9669 \\
2005 & 12438 & 16191 & 10959 \\
2006 & 22653 & 29501 & 19894 \\
2007 & 25062 & 32647 & 22001 \\
2008 & 32557 & 42423 & 28509 \\
2009 & 38060 & 49615 & 33222 \\
2010 & 42230 & 55023 & 37053 \\
2011 & 48585 & 63338 & 42409 \\
2012 & 53519 & 69731 & 47009 \\
2013 & 50132 & 65314 & 44067 \\
2014 & 128747 & 167982 & 111483 \\
2015 & 128399 & 298139 & 196893 \\
2016 & 238772 & 311640 & 206124 \\
2017 & 272376 & 355563 & 234759 \\
2018 & 268331 & 350298 & 231193 \\
\hline
\end{tabular}

\subsection{Analysis of the Lotka-Volterra Model Based on the} Evolution of High-Value Patents in Reverse Innovation in Local Enterprises

4.3.1. Model Parameter Calculation. We estimated the parameters of equations (1) and (2). The stability tests are shown in Tables 3-5.

The parameters were introduced into the discrete-time equation (2), and we calculated the estimated parameters of the influence coefficients in each of the three dimensions, as shown in Table 6.

We transformed the parameters of the discrete-time equations and calculated the parameters of the continuous equations (1), as shown in Table 7.

Then, we created a Lotka-Volterra model in the three dimensions to explain the evolution of the high-value patents of Huawei as follows: 


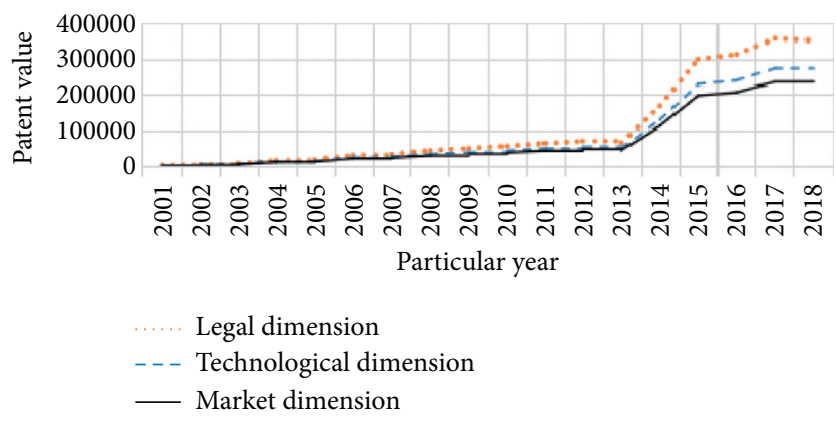

Figure 5: Value change of Huawei patents in the technology, law, and market dimensions (2001-2018).

TABLE 3: Stability test of parameter estimation of the technology dimension.

\begin{tabular}{lccc}
\hline & Coefficient & Std. error & t-statistic \\
\hline$\alpha_{1}$ & 1.008853 & 0.263892 & 3.822980 \\
$\beta_{1}$ & -0.011480 & 0.013619 & -0.842924 \\
$\gamma_{1}$ & 0.008296 & 0.009485 & 0.874628 \\
$\xi_{1}$ & 0.000754 & 0.001442 & 0.523118 \\
R-squared & 0.955112 & Mean dependent var & 0.4145 \\
Adjusted R-squared & 0.944754 & S.D. dependent var & 0.3976 \\
S.E. of regression & 23270.73 & Akaike info criterion & 86967.03 \\
Sum squared resid & $7.04 \mathrm{E}+09$ & Schwarz criterion & 99005.39 \\
Log likelihood & -192.7759 & Hannan-Quinn criterion & 23.15010 \\
Durbin-Watson stat & 1.734431 & & 23.34615 \\
& & & 23.16959 \\
\hline
\end{tabular}

$$
\left\{\begin{array}{l}
\dot{V}_{1}=\frac{\mathrm{d} V_{1}}{\mathrm{~d} t}=V_{1}\left(0.00876-0.01145 V_{1}+0.00826 V_{2}+0.00075 V_{3}\right) \\
\dot{V}_{2}=\frac{\mathrm{d} V_{2}}{\mathrm{~d} t}=V_{2}\left(0.00886+0.00826 V_{2}-0.01141 V_{1}+0.00075 V_{3}\right) \\
\dot{V}_{3}=\frac{\mathrm{d} V_{3}}{\mathrm{~d} t}=V_{3}\left(0.00856+0.00077 V_{3}+0.00834 V_{1}-0.01155 V_{2}\right)
\end{array}\right.
$$

4.3.2. Value Degree of the Best High-Value Patents in the Three Dimensions. We obtained the equilibrium conditions when all of the equations in the equation group (10) were equal to zero. When the equilibrium conditions were reached, the company obtained an optimal position for their high-value patents. The equilibrium conditions were obtained as follows:

$$
\left\{\begin{array}{l}
\dot{V}_{1}=\frac{\mathrm{d} V_{1}}{\mathrm{~d} t}=V_{1}\left(0.00876-0.01145 V_{1}+0.00826 V_{2}+0.00075 V_{3}\right)=0 \\
\dot{V}_{2}=\frac{\mathrm{d} V_{2}}{\mathrm{~d} t}=V_{2}\left(0.00886+0.00826 V_{2}-0.01141 V_{1}+0.00075 V_{3}\right)=0 \\
\dot{V}_{3}=\frac{\mathrm{d} V_{3}}{\mathrm{~d} t}=V_{3}\left(0.00856+0.00077 V_{3}+0.00834 V_{1}-0.01155 V_{2}\right)=0
\end{array}\right.
$$

According to the convergence conditions of the above model, Huawei's high-value patents met the conditions of equation (7), which means that the values of Huawei's highvalue patents in technology, law, and market can reach the highest point at the same time. This point can be seen as an optimal position for evolution of the high-value patents. The value degree of each dimension of the optimal point can be calculated as follows.

By reducing the dimension, we obtained equation (12) from (11): 
TABLE 4: Stability test of parameter estimation of the law dimension.

\begin{tabular}{|c|c|c|c|c|}
\hline & Coefficient & Std. error & $t$-statistic & Prob \\
\hline$\alpha_{2}$ & 1.008929 & 0.264049 & 3.820399 & 0.0021 \\
\hline$\beta_{2}$ & 0.008289 & 0.009490 & 0.873487 & 0.3982 \\
\hline$\gamma_{2}$ & -0.011469 & 0.013626 & -0.841753 & 0.4151 \\
\hline$\xi_{2}$ & 0.000753 & 0.001443 & 0.521677 & 0.6107 \\
\hline $\mathrm{R}$-squared & 0.955099 & \multicolumn{2}{|c|}{ Mean dependent var } & 113468.8 \\
\hline Adjusted R-squared & 0.944738 & \multicolumn{2}{|c|}{ S.D. dependent var } & 129262.9 \\
\hline S.E. of regression & 30387.03 & \multicolumn{2}{|c|}{ Akaike info criterion } & 23.68374 \\
\hline Sum squared resid & $1.20 E+10$ & \multicolumn{2}{|c|}{ Schwarz criterion } & 23.87979 \\
\hline Log likelihood & -197.3118 & \multirow{2}{*}{\multicolumn{2}{|c|}{ Hannan-Quinn criterion }} & 23.70323 \\
\hline Durbin-Watson stat & 1.733973 & & & \\
\hline
\end{tabular}

$$
\left\{\begin{array}{l}
\frac{\mathrm{d} V_{2} / \mathrm{d} t}{\mathrm{~d} V_{1} / \mathrm{d} t}=\frac{d V_{2}}{d V_{1}}=\frac{V_{2}\left(0.00886+0.00826 V_{2}-0.01141 V_{1}+0.00075 V_{3}\right)}{V_{1}\left(0.00876-0.01145 V_{1}+0.00826 V_{2}+0.00075 V_{3}\right)}=0, \\
\frac{\mathrm{d} V_{3} / \mathrm{d} t}{\mathrm{~d} V_{1} / \mathrm{d} t}=\frac{d V_{3}}{d V_{1}}=\frac{V_{3}\left(0.00856+0.00077 V_{3}+0.00834 V_{1}-0.01155 V_{2}\right)}{V_{1}\left(0.00876-0.01145 V_{1}+0.00826 V_{2}+0.00075 V_{3}\right)}=0, \\
\frac{\mathrm{d} V_{3} / \mathrm{d} t}{\mathrm{~d} V_{2} / \mathrm{d} t}=\frac{d V_{3}}{d V_{2}}=\frac{V_{3}\left(0.00856+0.00077 V_{3}+0.00834 V_{1}-0.01155 V_{2}\right)}{V_{2}\left(0.00886+0.00826 V_{2}-0.01141 V_{1}+0.00075 V_{3}\right)}=0 .
\end{array}\right.
$$

By solving the equations, we obtained the value degree of Huawei's optimal high-value patents in the three dimensions, as shown in Table 8:

We drew the optimal point on a three-dimensional coordinate diagram (Figure 6). The intersection of the three planes is the optimal point: the optimal value point of Huawei's high-value patents in the three dimensions.

4.3.3. Evolution Path Analysis. We used the Runge-Kutta fourth-order method to perform a numerical simulation to show the evolution path of the high-value patents in reverse innovation, as shown in Figure 7.

The circles in the figure represent the actual calculated year data, and the asterisks represent the predicted year data. The scatter points in the figure represent the value degree of Huawei's annual patent collection in terms of technology, law, and market. When the scatter distribution is relatively dense, the value degree changes slightly, and when the scatter distribution is sparse, the value degree changes greatly. The line between the scatter points is shown in the figure. The blue line represents the evolution path of the patent value, the black arrow represents the trajectory, and the red arrow represents the predicted trajectory of the model.

Compared with the theoretical analysis of the formation path of high-value patents in reverse innovation in local enterprises, we found that the evolution path of Huawei's high-value patents is basically consistent with the theoretical analysis (see Figure 2). In the domestic market stage from 2001 to 2011, the value degree of Huawei's patents in the three dimensions of technology, law, and market was relatively low, and development was slow. In the early stage of reverse innovation, Huawei's high-value patent evolution followed the general development law of local enterprises, that is, it began to rely on the huge market demand of the region (domestic or developing countries) to obtain a competitive advantage. From 2012 to 2018, that is, from Huawei's reverse innovation to entry in the overseas markets, the value degree of its high-value patents in both the technical and legal dimensions significantly increased, and the growth of the technological value was greater than the legal value. At the same time, at this stage, the market value of its patents also showed a substantial increase, indicating that, with the deepening of Huawei's reverse innovation strategy, when its new products and technologies are successfully reversed to the market in developed countries, the technical value and legal value of its patents are greatly improved compared with those in China. The significant improvement of the technical value indicates that Huawei has made outstanding achievements in technological catchup. In fact, Huawei has successfully achieved certain leading advantages in some key core technology fields (such as 5G communication). At the same time, the market value of its patents has also increased rapidly, which shows that Huawei has not only achieved obvious advantages in technology but also made considerable achievements in developing markets in developed countries and meeting the needs of local consumers.

From the data, Huawei's optimal high-value patent collection appeared in 2017 and 2018 and will now decline according to the data forecast. We speculate that the reason for this decline may be that Huawei had more patent layouts in the $5 \mathrm{G}$ field with high technology value around 2017 and 2018. Of course, the period after 2018 is the forecasted value of the data. Since the forecasted 
TABLE 5: Stability test of parameter estimation of the market dimension.

\begin{tabular}{|c|c|c|c|c|}
\hline & Coefficient & Std. error & t-statistic & Prob \\
\hline$\alpha_{3}$ & 1.008668 & 0.262033 & 3.849388 & 0.0020 \\
\hline$\beta_{3}$ & 0.000775 & 0.001434 & 0.540429 & 0.5980 \\
\hline$\gamma_{3}$ & 0.008385 & 0.009432 & 0.889013 & 0.3902 \\
\hline$\xi_{3}$ & -0.011614 & 0.013542 & -0.857598 & 0.4066 \\
\hline $\mathrm{R}$-squared & 0.955354 & \multicolumn{2}{|c|}{ Mean dependent var } & 75306.76 \\
\hline Adjusted R-squared & 0.945051 & \multicolumn{2}{|c|}{ S.D. dependent var } & 85214.13 \\
\hline S.E. of regression & 19975.13 & \multicolumn{2}{|c|}{ Akaike info criterion } & 22.84469 \\
\hline Sum squared resid & $5.19 \mathrm{E}+09$ & \multicolumn{2}{|c|}{ Schwarz criterion } & 23.04074 \\
\hline Log likelihood & -190.1798 & \multirow{2}{*}{\multicolumn{2}{|c|}{ Hannan-Quinn criterion }} & 22.86418 \\
\hline Durbin-Watson stat & 1.739413 & & & \\
\hline
\end{tabular}

TABle 6: Parameter estimation of discrete-time equation (2).

\begin{tabular}{lccccr}
\hline \multirow{2}{*}{ Dimension } & \multicolumn{2}{c}{ Parameter } & $\xi_{i}$ & $R^{2}$ & DW \\
& $\alpha_{i}$ & $\beta_{i}$ & $\gamma_{i}$ & 0.000754 & 0.955112 \\
Technology & 1.008853 & -0.011480 & 0.008296 & 0.000753 & 0.955099 \\
Law & 1.008929 & 0.008289 & -0.011469 & -0.011614 & 0.955354 \\
Market & 1.008668 & 0.000759 & 0.008385 & 1.734431 \\
\hline
\end{tabular}

TABle 7: Parameter estimation of continuous equation (1).

\begin{tabular}{|c|c|c|c|c|}
\hline \multirow{2}{*}{ Dimension } & \multicolumn{4}{|c|}{ Parameter } \\
\hline & $a_{i}$ & $b_{i}$ & $c_{i}$ & $d_{i}$ \\
\hline Technology & 0.008761506 & -0.011449695 & 0.008263693 & 0.000746719 \\
\hline Law & 0.008860628 & 0.008263283 & -0.011409304 & 0.000746682 \\
\hline Market & 0.008563231 & 0.000766708 & 0.008344171 & -0.011550404 \\
\hline
\end{tabular}

TABLE 8: Values of Huawei's optimal high-value patents in the three dimensions.

\begin{tabular}{lccc}
\hline & Technology value & Law value & Market value \\
\hline Optimal point (V1, V2, V3) & 3.628934612 & 3.641341302 & 3.612820702 \\
\hline
\end{tabular}

value is based on the long-term smooth growth rate of the data, it cannot reflect the momentum after the rapid growth of 5G technology in 2017 and 2018. Therefore, more data are needed to test whether the optimal value was reached in 2017 and 2018. However, according to the actual data, the actual evolution path of Huawei's highvalue patents is more consistent with the theoretical and practical analyzes.

4.4. Management Suggestions. According to the above analysis, we present some management suggestions as follows:

(1) In reverse innovation, the cultivation of high-value patents in local enterprises should consider the value development of technology, law, and the market. However, this does not mean the enterprises should develop the values in these three dimensions at the same time. Local enterprises can choose whether to develop their technology or market value according to the market conditions and their capabilities. For example, in the initial phase of reverse innovation, when the local enterprises are weak in the technology area but have advantages in costs and demands in emerging markets, they can capitalize on these advantages in the short term to increase their technology investment and accumulate their technology capabilities, thereby grasping opportunities to reverse their new products and technologies to developed countries. In this process, the local enterprises should follow the newest technologies' development and survey the global patents when they obtain some success in technology innovation, especially in the key technologies of industrial development. When they successfully reverse new products and technologies to developed countries, they need to continuously improve their technology and quality of new products to establish and maintain a long-term advantage in the global market.

(2) In reverse innovation, a patent's law value is often ignored by local enterprises. Since the intellectual property protection system is fragile in developing countries, local enterprises usually do not pay enough attention to intellectual property protection, which leads to the low law value of their patents and a difficulty reversing their new products to developed countries where strict intellectual property protection is required. 


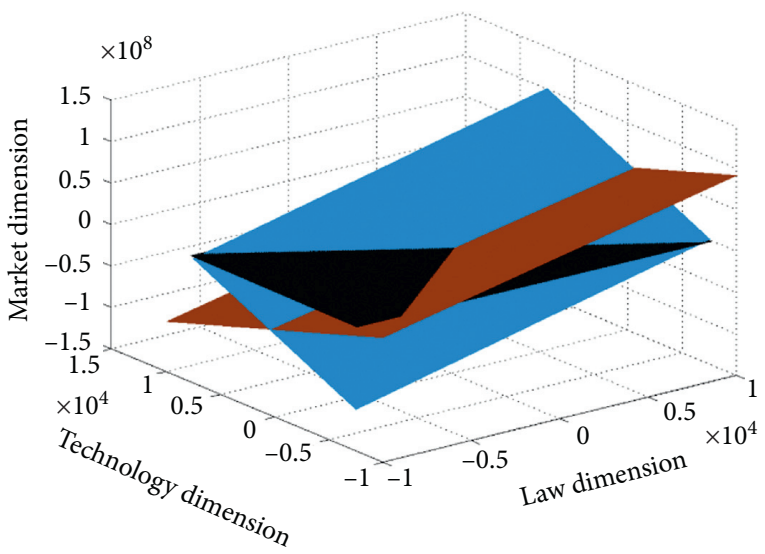

FIgURE 6: Formation of the optimal point of Huawei's high-value patents in the three dimensions.

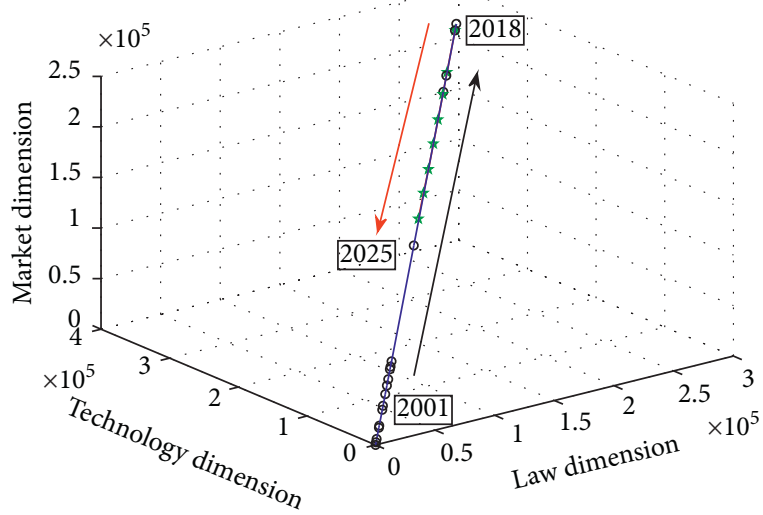

FIgURE 7: Evolution path of Huawei's high-value patents.

Even if some new products were successfully reversed to developed countries, it would be hard to maintain this situation for the long term due to the low law value of the patents and the probability of intellectual property disputes. Therefore, in the process of reverse innovation, local enterprises must pay attention to cultivate high law value in their patents, improving the written quality of the patent applications, enhancing the stability and clearance of their legal claims, etc. Especially, in the markets of developed countries, a patent's law value is sometimes a decisive factor in the successful reverse innovation in local enterprises.

(3) The formation of high-value patents in reverse innovation in local enterprises is a long-term and complex evolution process, especially with the optimal high-value patents that can be formed after a long period of technology catch-up in developing countries. To obtain successful inverse innovation, local enterprises must make efforts to improve the value of their patents according to the changes in their external situation and their inner capability and balance the relationships among the technology, law, and market values. Especially, when local enterprises gain an advantage in certain technologies, they must enhance their strategies in the global layout of their high-value patents and increasingly improve the whole quality of their patents.

\section{Conclusion}

This paper discussed the evolution of high-value patents in reverse innovation in local enterprises based on the ecological perspective. We draw the following conclusions.

(1) High-value patents show their value in three dimensions, i.e., technology, law, and market. These values affect each other as the situation changes. The formation of high-value patents is a long-term evolving process resulting from the interaction among the values of these three dimensions with changes in the external situation.

(2) For reverse innovation in local enterprises, the formation of high-value patents reflects a long-term technology catch-up process of developing countries. We built a Lotka-Volterra model of the three dimensions to explain this complex process and simulated the evolution path of high-value patents in reverse innovation in local enterprises.

(3) We used Huawei's data to analyze the evolution path of its high-value patents in reverse innovation and found that the results were consistent with our theoretical model analysis. Therefore, through this model, we proposed some management strategies for cultivating high-value patents in reverse innovation in local enterprises.

There are some limitations in our study. For example, there may be some other paths in the formation of highvalue patents that we have not discussed, and more cases should be analyzed to test the model. These limitations also provide interesting issues for future studies [38-43].

\section{Appendix}

Patent value calculation formula (operation manual of patent value analysis index system)

Technology value $=($ Advanced $* 15 \%+$ Industry development trend $* 10 \%+$ Alternative $* 20 \%$ ) (Precited patents, $45 \%)+($ Applicable $* 20 \%+$ Supporting technology dependency $* 15 \%)$ (Family patents, $35 \%)+($ Maturity $* 20 \%)$ (Not involving infringement patents, 20\%)

Law value $=($ Judgment of patent infringement $*$ $20 \%+$ Noncircumvention $* 30 \%+$ Patent licensing * $5 \%$ ) (No infringement patent, 55\%)+(Multinational application * 15\%) (Patent of the same family, $15 \%)+($ Dependency $* 15 \%+$ Validity $* 15 \%)$ (Front citation patent, $30 \%)$

Market value $=($ Market application $* 25 \%+$ Market share * 20\%) (Family patent, $45 \%)+($ Market scale prospect $* 20 \%+$ Competition $* 20 \%$ ) (Front cited patent, $40 \%)+($ Policy adaptability $* 15 \%)$ (No infringement patent, 15\%) 


\section{Data Availability}

The structural data used to support the findings of this study are included within the supplementary information files. The data used to support the findings of this study were supplied by INNOGRAPHY under license and so cannot be made freely available. Requests for access to these data should be made to pay.

The data of this paper is to search all patent information of INNOGRAPHY Huawei company and get the number of patents by screening invention patents and patent intensity. The number of references, the number of families, and the number of infringements are selected. The data provided in the supplementary materials are the number of patents sorted out by the author.

\section{Conflicts of Interest}

The authors declare that they have no conflicts of interest.

\section{Acknowledgments}

The project was supported by the National Natural Science Foundation of China (nos. 71562001 and 72062002).

\section{Supplementary Materials}

The data provided in the supplementary materials are the number of patents sorted out by the author. (Supplementary Materials)

\section{References}

[1] J. R. Immelt, V. Govindarajan, and C. Trimble, "How GE is disrupting itself," Harvard Business Review, vol. 35, no. 10, 2009.

[2] V. Govindarajan and R. Ramamurti, "Reverse innovation, emerging markets, and global strategy," Global Strategy Journal, vol. 1, no. 3-4, pp. 191-205, 2011.

[3] H. Luo and Q. Zhang, "Research on the breakthrough technological innovation process of new and technological small enterprises from the perspective of knowledge management," Science of Science and Management of S.\&.T. vol. 3, pp. 143-151, 2015.

[4] P. Cao and Y. Zeng, "Research dynamics and analysis model construction of reverse innovation," Science and technology progress and countermeasures, vol. 32, no. 17, pp. 22-26, 2015.

[5] Y. Cao and L. Zhao, "Research on the mechanism of patent acquisition, patent protection, patent commercialization and technological innovation performance," Scientific Research Management, vol. 34, no. 8, pp. 42-52, 2013.

[6] T. Dong, "High value patents provide inexhaustible new impetus for enterprise transformation and upgrading," China Science and Technology Industry, vol. 7, pp. 78-80, 2018.

[7] B. Wei, L. Liu, and G. Rao, "Giving full play to the advantages of examination Resources to help cultivate high-value patents," Chinese Invention and Patent, vol. 15, no. 4, pp. 25-29, 2018.

[8] Y. Su and W. Sun, "Analyzing a closed-loop supply chain considering environmental pollution using the NSGA-II," IEEE Transactions on Fuzzy Systems, vol. 27, no. 5, pp. 1066-1074, 2019.
[9] Y. Su and W. Sun, "Sustainability evaluation of the supply chain with undesired outputs and dual-role factors based on double frontier network DEA," Soft Computing, vol. 22, no. 16 , pp. 5525-5533, 2018.

[10] Y. Su and T. C. Li, "Simulation analysis of knowledge transfer in a knowledge alliance based on a circular surface radiator model," Complexity, vol. 2020, Article ID 4301489, 27 pages, 2020.

[11] Z. Yang, T. Ouyang, X. Fu, and X. Peng, “A decision-making algorithm for online shopping using deep-learning-based opinion pairs mining and q-rung orthopair fuzzy interaction Heronian mean operators," International Journal of Intelligent Systems, vol. 35, no. 5, pp. 783-825, 2020.

[12] N. Wang, Research on the Impact of Reverse Innovation Transfer of Subsidiaries of Multinational Companies: Theoretical and Empirical Research, University of Foreign Economic and Trade, Beijing, China, 2016.

[13] C. Simone, D. M. Alberto, and P. Andrea, "Reverse innovation at speres: a case study in China," Research Technology Management, vol. 57, no. 4, pp. 28-34, 2014.

[14] M. Nan, Research on Key Success Factors of Reverse Innovation in Electronic Information Industry, Dalian University of Technology, Dalian, China, 2016.

[15] Y. Xu, X. Wang, N. Xu, and S. Zheng, "The process and key factors of reverse innovation in late development engineering technology service enterprises," Scientific Research Management, vol. 38, no. 6, pp. 9-17, 2017.

[16] Y. Yu, Research on Key Influencing Factors of Reverse Innovation in China's Engineering Technology Service Enterprises, Dalian University of technology, Dalian, China, 2014.

[17] N. Xu and Z. Peng, "Case study on local product development capability, innovation network and reverse innovation of latecomers," Research and Development Management, vol. 29, no. 5, pp. 99-112, 2017.

[18] R. Li, W. Zhou, J. Rong, and Z. Kong, "Analysis of cited characteristics of high value enterprise patents-taking the world's top 500 enterprise patents as an example," Journal of the China Society for Scientific and Technical Information, vol. 34, no. 9, pp. 899-911, 2015.

[19] Q. Zhang, "Invention patent: the weapon of enterprise core competitiveness," China Invention and Patent, vol. 6, pp. 40-41, 2014.

[20] T. Zhang and G. Li, "Research on enterprise intellectual property value and its evaluation," Reformation and Strategy, vol. 8, pp. 23-26, 2006.

[21] T. Ma and X. Zhao, "The connotation of high-value patent and its restricted factors," Chinese Invention and Patent, vol. 15, no. 3, pp. 24-28, 2018.

[22] X. Wan and X. Zhu, "Evaluation index system and fuzzy comprehensive evaluation of patent value," Scientific Research Management, vol. 2, pp. 185-191, 2008.

[23] J. Ji and L. Dong, "Development and application of QR code technology," Management \& Technology of SME, vol. 27, pp. 290-291, 2013.

[24] Q. Zhu, Research on Key Factors Influencing Technology Source Acquisition in the Process of Reverse Innovation, Dalian University of Technology, Dalian, China, 2013.

[25] D. Wang, "Research on core rigidity in strategic change-taking Kodak as an example," Science of Science and Management of S.ङ.T. vol. 34, no. 5, pp. 97-105, 2013.

[26] X. Zhang, "Will dinosaurs die out?-_how American famous enterprises get out of the trough," Manager Journal, vol. 2, pp. 41-42, 1995. 
[27] Y. Hou, W. Liu, and Y. Liu, "Research on the international development path and influence mechanism of independent innovation system of China's communication industry-taking Huawei as an example," Science and Technology for Development, vol. 11, pp. 32-40, 2011.

[28] Z. Xing, G. Ma, Y. Sun, and G. Liu, "Construction and promotion of high value patent cultivation system," Chinese Universities Science and Technology, vol. Z1, pp. 50-53, 2019.

[29] J. Zhang and X. Zhang, "Experience sharing of claims interpretation in patent infringement determination," Chinese Invention and Patent, vol. 16, no. 10, pp. 98-103, 2019.

[30] S. Yang, Y. Wang, H. Chen, L. Zhou, B. Li, and L. Dai, "Research on patent legal value evaluation," High Tech Communication, vol. 26, no. z1, pp. 815-823, 2016.

[31] D. Zeng, "High value patent screening," Science and Technology Innovation and Application, vol. 14, pp. 4-6, 2019.

[32] G. Giancarlo, "Giuseppe palomba and the lotka-volterra equations," Rendiconti Lincei, vol. 19, no. 4, pp. 347-357, 2008.

[33] J. F. Moore, "Predators and prey: a new ecology of competition," Harvard Business Review, vol. 71, no. 3, pp. 75-86, 1993.

[34] Y. Chen and F. Xie, "Bionics research on the evolution path of photovoltaic industry ecological innovation system based on Lotka voterra model," Research and Development Management, vol. 24, no. 3, pp. 74-84, 2012.

[35] H.-T. Wang and T.-C. Wang, "Application of the grey LotkaVolterra model to forecast the diffusion and competition analysis of the TV and smartphone industries," Technological Forecasting and Social Change, vol. 106, pp. 37-44, 2016.

[36] J. Dan and G. Dong, "Research on reverse innovation path of emerging market latecomers: case study from Huawei," Science \& Technology Progress and Policy, vol. 34, no. 2, pp. 87-93, 2017.

[37] X. Fan, Research on Marketing Strategy of JL Company, Dalian University of Technology, Dalian, China, 2017.

[38] M. B. Felipe, M. O. Moacir de, F. S. Franciane, and O. C. Ronald de, "The reverse transfer of innovation of foreign subsidiaries of Brazilian multinationals," European Management Journal, vol. 30, no. 3, pp. 219-231, 2012.

[39] F. S. Franciane, S. Roberto, L.-V. Henry, and T. Fredrik, "Determinants of reverse knowledge transfer for emerging market multinationals: the role of complexity, autonomy and embeddedness," Revista de Administração, vol. 52, no. 2, pp. 176-188, 2017.

[40] X. Han and Y. Lei, "Theoretical and practical analysis of cultivating high value patents," Chinese Invention and Patent, vol. 14 , no. 12 , pp. 8-14, 2017.

[41] V. Rowthorn, A. J. Plum, and J. Zervos, "Legal and regulatory barriers to reverse innovation," Annals of Global Health, vol. 82 , no. 6 , pp. 991-1000, 2016.

[42] J. Wang, L. Xue, and Z. Liang, "Multinational R\&D in China: from home-country-based to host-country-based," Innovation, vol. 14, no. 2, pp. 192-202, 2012.

[43] J. Zhang and J. Sun, "Research on technology catching up mode and path of communication enterprises from the perspective of standard essential patents," Forum on Science and Technology in China, vol. 4, pp. 112-121, 2018. 